\title{
Article \\ Prevalence and Characterization of Methicillin-Resistant Staphylococcus aureus from Community- and Hospital-Associated Infections: A Tertiary Care Center Study
}

\author{
Puthiya Purayil Preeja ${ }^{1}$, Sanath H. Kumar ${ }^{2}$ (D) and Veena Shetty ${ }^{1, *(1)}$ \\ 1 Department of Microbiology, KS Hegde Medical Academy, Nitte (Deemed to Be University), \\ Mangalore 5750181, India; preejasharath@gmail.com \\ 2 QC Laboratory, Post Harvest Technology, ICAR-Central Institute of Fisheries Education, Mumbai 400061, \\ India; sanathkumar@cife.edu.in \\ * Correspondence: veenashetty@nitte.edu.in
}

check for updates

Citation: Preeja, P.P.; Kumar, S.H.; Shetty, V. Prevalence and Characterization of

Methicillin-Resistant Staphylococcus aureus from Community- and Hospital-Associated Infections: A Tertiary Care Center Study. Antibiotics 2021, 10, 197. https:// doi.org/10.3390/antibiotics10020197

Academic Editor: Italo

Francesco Angelillo

Received: 14 January 2021

Accepted: 16 February 2021

Published: 18 February 2021

Publisher's Note: MDPI stays neutral with regard to jurisdictional claims in published maps and institutional affiliations.

Copyright: (C) 2021 by the authors Licensee MDPI, Basel, Switzerland. This article is an open access article distributed under the terms and conditions of the Creative Commons Attribution (CC BY) license (https:// creativecommons.org/licenses/by/ $4.0 /)$.

\begin{abstract}
The community-associated methicillin-resistant Staphylococcus aureus (CA-MRSA) has become increasingly prevalent in both community and hospital settings. The aim of this study was to determine the prevalence, molecular characteristics and antibiotic resistance profiles of CA-MRSA from community- and hospital-associated infections in a tertiary care hospital in Mangalore, India. Of 520 S. aureus isolates, 362 were from inpatients (IP) and 158 were from outpatients (OP). Onehundred and thirty-two MRSA isolates obtained from 94 inpatients and 38 outpatients with complete clinical details were further analyzed. Of these, 81 (61.4\%) were CA-MRSA (IP-47.9\%, OP-94.7\%) and 51 (38.6\%) were HA-MRSA (IP-52.1\%, OP-5.3\%). All (100\%) MRSA isolates were mecA gene positive. SCCmec typing identified SCCmec type IV (50.6\%) and SCCmec type V (66.7\%) in CA-MRSA, while SCCmec type I (41.2\%), SCCmec type III (19.6\%), SCCmec type IV (31.4\%) and SCCmec type V $(25.5 \%)$ were detected in HA-MRSA isolates. The Panton-Valentine Leukocidin (PVL) gene was found in $70.4 \%$ of CA-MRSA, $43.1 \%$ of HA-MRSA with SCCmec type IV and SCCmec type V, and in $7.8 \%$ of true HA-MRSA. The antibiotic resistance profiles were determined by the disc diffusion method. Resistance to cefoxitin was used to identify MRSA. A significant difference $(p<0.05)$ was observed between CA-MRSA and HA-MRSA with respect to resistance against cephalexin, cefotaxime, levofloxacin, linezolid and teicoplanin. CA-MRSA was predominantly resistant to ciprofloxacin (86.4\%), erythromycin $(66.7 \%)$, ofloxacin $(49.4 \%)$, cefotaxime $(44.4 \%)$, gentamicin $(40.7 \%)$ and clindamycin $(40.7 \%)$, while HA-MRSA showed resistance against ciprofloxacin (80.4\%), erythromycin $(80.1 \%)$, cefotaxime $(70.6 \%)$,ofloxacin $(58.8 \%)$, clindamycin $(47.1 \%)$ and levofloxacin $(41.2 \%)$. This study reports the prevalence of CA-MRSA in community and hospital settings and the possibility of multidrug-resistant CA-MRSA replacing HA-MRSA in hospitals. The observations from our study emphasize the need for urgent measures to manage this emerging crisis in healthcare settings.
\end{abstract}

Keywords: CA-MRSA; PVL; SCCmec typing; multi-drug resistance; HA-MRSA

\section{Introduction}

Staphylococcus aureus is a highly versatile bacterial pathogen capable of causing a wide range of infections in humans, from mild skin infections to severe systemic diseases such as pneumonia. Since the first report of methicillin-resistant $S$. aureus (MRSA) in the 1960s, MRSA has been recognized as a pathogen of global concern [1]. Although MRSA infections were originally acquired only from hospital settings (HA-MRSA), community outbreaks were first reported in the 1990s from Australia and the United States of America, and subsequently from across the world [2,3]. Community-associated methicillin-resistant S. aureus (CA-MRSA) strains were originally restricted to the community and found mainly in healthy, young patients [4]. However, CA-MRSA infections are now being increasingly reported in community and hospital settings as well [5-7]. According to the US Centers for 
Disease Control and Prevention (CDC), a MRSA infection can be categorized as CA-MRSA when the patient has no history of surgery, hospitalization or residence in a long-term care facility within the year before infection, has no percutaneous device or indwelling catheter, has not undergone dialysis within the previous year, hospitalization $<48 \mathrm{~h}$ before MRSA culture, or has no history of previous MRSA infection or colonization [8]. CAMRSA can cause infections in healthy individuals with no hospital-associated risk factors, is more susceptible to non- $\beta$-lactam antibiotics and possesses the virulence-associated Panton-Valentine Leukocidin (PVL) gene, which is responsible for leucocytosis and tissue necrosis $[9,10]$. Methicillin resistance, due to altered penicillin binding protein (PBP-2a), is encoded by the mecA gene present on a mobile genetic element present in staphylococcal cassette chromosome mec(SCCmec) [11]. So far, 14 SCCmec sequence types have been reported [12]. Studies showed that CA-MRSA contain SCCmec types IV and V, mostly with the PVL gene, while HA-MRSA carry SCCmec types I, II and III [13]. HA-MRSA are commonly associated with nosocomial infections and are resistant to non- $\beta$-lactam antibiotics such as fluoroquinolones, macrolides and aminoglycosides [14]. HA-MRSA generally do not possess the PVL gene and belong to the SCCmec types I, II and III [15]. CA-MRSA are often resistant to multiple drugs including $\beta$-lactams, aminoglycosides, fluoroquinolones and tetracyclines [16-18]. The infiltration of CA-MRSA into hospital settings in different countries is a major concern [19-22]. CA-MRSA infections in Asian countries range from $2.5 \%$ to $39 \%$ [23]. The occurrence of multidrug-resistant PVL-positive CA-MRSA in hospital settings is frequently reported in India [24,25].

The literature shows that limited data is available on the molecular epidemiology, prevalence and antibiogram of CA-MRSA from the southern part of India. The aim of this study was to gain a better understanding of the prevalence, molecular characteristics and antibiotic resistance profiles of CA-MRSA from community- and hospital-acquired infections in a tertiary care hospital in Mangalore, India. Our study revealed the prevalence of PVL-positive antibiotic-resistant CA-MRSA not only in the community, but also in hospital settings.

\section{Materials and Methods}

This is a cross-sectional study carried out in a tertiary care hospital in Mangalore, India. Ethical approval (NU/CEC/Ph.D- 65/2012) for the study was obtained from the Central Ethical Committee, Nitte (Deemed to be University). The study was carried out from October 2014 to December 2016.

\subsection{Isolation of S. aureus and Phenotypic Confirmation of MRSA}

\subsubsection{Isolation of $S$. aureus}

The study's information was given to the patients, and with their consent, the demography, age, sex and other clinical details were documented. The term "outpatient" was used for patients visiting the hospital without a hospital stay, while "inpatient" was used for patients requiring at least an overnight hospitalization. Out of 520 patients diagnosed as having $S$. aureus infection, 132 MRSA isolates with complete clinical details were considered for further study. These 132 MRSAs were isolated from various clinical samples such as pus (111), blood (18), a throat swab (1), body fluids (1) and urine (1) (Table 1).

Table 1. Isolation of MRSA from various clinical samples.

\begin{tabular}{ccccc}
\hline Sample & CA-MRSA $(\boldsymbol{n}=\mathbf{8 1})$ & HA-MRSA $(\boldsymbol{n}=\mathbf{5 1})$ & Chi-Square Value & $\boldsymbol{p}$-Value \\
\hline Pus & 72 & 39 & & \\
Blood & 07 & 11 & 7.256 & 0.123 \\
Body fluid & 00 & 01 & & \\
Throat swab & 01 & 00 & & \\
Urine & 01 & 00 & & \\
\hline
\end{tabular}


Blood agar and MacConkey agar (Hi-Media, Mumbai, India) were inoculated with the sample and incubated at $37^{\circ} \mathrm{C}$ for $24-48 \mathrm{~h}$. The isolates were identified by colony morphology, Gram staining, catalase, coagulase and mannitol fermentation tests [26]. S. aureus ATCC 25923 was used as the reference strain for the biochemical tests.

\subsubsection{Phenotypic Confirmation of Methicillin Resistance}

Methicillin resistance was tested using a cefoxitin disc $(30 \mu \mathrm{g})$ by the disc diffusion method on Mueller Hinton agar (Hi-Media, Mumbai). Isolates showing a zone of inhibition of $\leq 21 \mathrm{~mm}$ with cefoxitin were considered methicillin-resistant [27]. Further confirmation of methicillin resistance was done by determining the minimum inhibitory concentration (MIC) using the EzyMIC ${ }^{\mathrm{TM}}$ strip (Hi-Media, Mumbai, India). Isolates with a cefoxitin MIC of $\geq 4 \mu \mathrm{g} / \mathrm{mL}$ were confirmed as MRSA. S. aureus ATCC 29213 (methicillin-sensitive, MSSA) and ATCC 43300 (methicillin-resistant, MRSA) were used as the reference strains. CA-MRSA was classified according to the CDC definition $[28,29]$.

\subsubsection{Antibiotic Susceptibility Testing}

The Kirby-Bauer disc diffusion method was used to determine the antibiotic susceptibility profiles of isolates on Mueller-Hinton agar. The zones of inhibition were interpreted according to the Clinical \& Laboratory Standards Institute (CLSI) guidelines [30]. The antibiotics (Hi-Media, Mumbai, India) used were amikacin (30 $\mu \mathrm{g})$,ampicillin $(10 \mu \mathrm{g})$, cephalexin $(30 \mu \mathrm{g})$, cefoxitin $(30 \mu \mathrm{g})$, cefotaxime $(30 \mu \mathrm{g})$, ciprofloxacin $(5 \mu \mathrm{g})$, clindamycin $(2 \mu \mathrm{g})$, chloramphenicol $(30 \mu \mathrm{g})$, trimethoprim-sulphamethoxazole $(25 \mu \mathrm{g})$, doxycycline $(30 \mu \mathrm{g})$, erythromycin $(15 \mu \mathrm{g})$, gentamicin $(10 \mu \mathrm{g})$, levofloxacin $(5 \mu \mathrm{g})$, linezolid $(30 \mu \mathrm{g})$, netilmicin $(30 \mu \mathrm{g})$, oxacillin $(1 \mu \mathrm{g})$, ofloxacin $(5 \mu \mathrm{g})$, penicillin $(10 \mathrm{U})$, rifampicin $(5 \mu \mathrm{g})$, tetracycline $(30 \mu \mathrm{g})$, tigecycline $(15 \mu \mathrm{g})$, teicoplanin $(30 \mu \mathrm{g})$ and vancomycin $(30 \mu \mathrm{g})$.

\subsection{Molecular Characterization of MRSA}

Methicillin resistance was confirmed by detecting the presence of the mecA gene by the polymerase chain reaction (PCR). CA-MRSA and HA-MRSA were differentiated using primers detecting the SCCmec and $l u k S / F-P V$ genes, which encode the PVL S/F bicomponent proteins using previously described PCR protocols (Table S1) [31-33]. For the preparation of DNA for PCR, a single bacterial colony from the nutrient agar was grown in Luria Bertani (LB) broth at $37^{\circ} \mathrm{C}$ for $24 \mathrm{~h}$, and $50 \mu \mathrm{l}$ of the broth culture was mixed with $450 \mu \mathrm{L}$ of $1 \mathrm{X}$ TE (10 mM Tris pH 8, $1 \mathrm{mM}$ EDTA) buffer. The mixture was heated in a dry bath at $98{ }^{\circ} \mathrm{C}$ for $10 \mathrm{~min}$, chilled immediately on ice and centrifuged. The supernatant containing DNA was stored at $-20^{\circ} \mathrm{C}$ until use.

All amplifications were done in a $30-\mu \mathrm{L}$ volume consisting of a 10X Taq buffer (100 mM Tris- $\mathrm{HCl}, 500 \mathrm{mM} \mathrm{KCl}$ and $15 \mathrm{mM} \mathrm{MgCl}_{2}$ (Hi-Media, Mumbai, India)), $200 \mu \mathrm{M}$ concentrations of each of the four dNTPs, 30 picomoles of forward and reverse primers, $1.5 \mathrm{U}$ of Taq polymerase (Hi-Media, Mumbai, India) and $2 \mu \mathrm{L}$ of DNA template. The amplifications were carried out in a thermocycler (Bio-Rad Laboratories, Inc., USA). The products of the PCR were separated on a $1.5 \%$ agarose gel stained with ethidium bromide $(0.5 \mu \mathrm{g} / \mathrm{mL})$ along with a $100 \mathrm{bp}$ DNA ladder (Hi- Media, Mumbai, India) and were photographed using a gel documentation system (Bio-Rad, USA).

The SCCmec PCR products were purified using a PCR purification kit (Thermo Fisher Scientific, USA) and sequenced by Sanger's dideoxy chain termination method (Bioserve Biotechnologies Pvt Ltd., Hyderabad, India).

\subsection{Statistical Analysis}

The data were analyzed using SPSS (Version 20.0, IBM Corp., Armonk, NY, USA) software. The collected information was summarized by using the frequency, percentage, mean and standard deviation. To compare the difference in antibiotic sensitivity with respect to CA-MRSA and HA-MRSA, Chi-square and Fishers exact tests were used. 


\subsection{Nucleotide Sequence Accession Number}

The nucleotide sequences derived in this study have been assigned the GenBank accession numbers MK995142 to MK995148 and MK975991 to MK975993.

\section{Results}

\subsection{Isolation of MRSA from Clinical Samples}

Of the 520 S. aureus isolated during the study period, 132 MRSA isolates were considered for a detailed study. Based on the criteria described in the methods section, $81(61.4 \%)$ isolates were identified as CA-MRSA and $51(38.6 \%)$ as HA-MRSA.

MRSA were isolated from various clinical samples such as pus, blood, a throat swab, body fluids and urine (Table 1$)$. Of the 132 MRSA cases, $94(71.2 \%)$ were inpatients and 38 $(28.8 \%)$ were outpatients. A significant difference was observed between the isolation of CA-MSSA and HA-MSSA from the inpatient and outpatient groups $(p<0.05)$ (Table S2). The patients included in this study were in the age range of 1 to 79 years with a median age of 40 years. The gender-wise analysis of the MRSA cases revealed that $78(59.1 \%)$ were males and $54(40.9 \%)$ were females. No significant difference $(p>0.05)$ was observed between the incidences of CA-MRSA and HA-MRSA with regards to the age, gender, sample types or mortality rates (Table 1) (Supplementary Tables S3-S5).

\subsection{Antibiotic Resistance Profiles of MRSA Isolates}

All (100\%) MRSA isolates were resistant to penicillin, cefoxitin and ampicillin (Table 2), while all MRSA isolates were susceptible to amikacin and vancomycin. CA-MRSA showed an increased susceptibility to netilmicin, linezolid, tigecycline, doxycycline, chloramphenicol, rifampicin and teicoplanin. A significant difference $(p<0.05)$ existed between CAMRSA and HA-MRSA with regard to resistance against cephalexin, cefotaxime ( $\beta$-lactam antibiotics), levofloxacin, linezolid and teicoplanin (non- $\beta$-lactam antibiotic) (Table 2). Altogether, 106 (80.3\%) MRSA isolates were multidrug-resistant, of which 60 were CA-MRSA and 46 were HA-MRSA.

Table 2. Antibiotic resistance profiles of MRSA.

\begin{tabular}{|c|c|c|c|c|c|}
\hline \multirow{3}{*}{ Antibiotic Class } & \multirow{3}{*}{ Antibiotics } & \multicolumn{2}{|c|}{ MRSA $(n=132)$} & \multirow{3}{*}{$\begin{array}{c}\text { Chi-Square } \\
\text { Value }\end{array}$} & \multirow{3}{*}{$p$-Value } \\
\hline & & CA-MRSA & HA-MRSA & & \\
\hline & & $(n=81)($ Resistant $\%)$ & $(n=51)($ Resistant \%) & & \\
\hline \multicolumn{6}{|c|}{$\beta$-Lactam antibiotics } \\
\hline \multirow{4}{*}{ Penicillins } & Ampicillin & $81(100)$ & $51(100)$ & NA & NA \\
\hline & Oxacillin & $81(100)$ & $51(100)$ & NA & NA \\
\hline & Penicillin & $81(100)$ & $51(100)$ & NA & NA \\
\hline & Cephalexin & $18(22.2)$ & $28(54.9)$ & 14.721 & $<0.001$ * \\
\hline \multirow{2}{*}{ Cephalosporins } & Cefoxitin & $81(100)$ & $51(100)$ & NA & NA \\
\hline & Cefotaxime & $36(44.4)$ & $36(70.6)$ & 8.627 & $0.003 *$ \\
\hline \multicolumn{6}{|c|}{ Non- $\beta$-Lactam antibiotics } \\
\hline \multirow{3}{*}{ Aminoglycosides } & Amikacin & $0(0)$ & $0(00)$ & NA & NA \\
\hline & Gentamycin & $33(40.7)$ & $20(39.2)$ & 0.030 & 0.862 \\
\hline & Netilmicin & $2(2.5)$ & $2(3.9)$ & 0.225 & 0.636 \\
\hline Fluroquinolones & Ciprofloxacin & $70(86.4)$ & $41(80.4)$ & 0.850 & 0.357 \\
\hline \multirow{2}{*}{ Macrolide } & Clindamycin & $33(40.7)$ & $24(47.1)$ & 0.509 & 0.475 \\
\hline & Erythromycin & $54(66.7)$ & $41(80.1)$ & 2.923 & 0.087 \\
\hline Sulphonamides & Trimethoprim-Sulfamethoxazole & $23(28.4)$ & $20(39.2)$ & 1.668 & 0.196 \\
\hline \multirow{2}{*}{ Quinolone } & Levofloxacin & $10(12.3)$ & $21(41.2)$ & 14.836 & $0.001 *$ \\
\hline & Ofloxacin & $40(49.4)$ & $30(58.8)$ & 1.120 & 0.290 \\
\hline Oxazolidinones & Linezolid & $0(0)$ & $6(11.8)$ & 9.983 & $0.002 *$ \\
\hline Rifamycin & Rifampicin & $9(11.1)$ & $8(15.7)$ & 0.584 & 0.445 \\
\hline Glycylcycline & Tigecycline & $0(0)$ & $1(2)$ & 1.600 & 0.206 \\
\hline \multirow{2}{*}{ Tetracycline } & Doxycycline & $5(6.2)$ & $5(9.8)$ & 0.589 & 0.443 \\
\hline & Tetracycline & $10(12.3)$ & $10(19.6)$ & 1.284 & 0.257 \\
\hline Chloramphenicol & Chloramphenicol & $3(3.7)$ & $3(5.9)$ & 0.342 & 0.558 \\
\hline \multirow{2}{*}{ Glycopeptide } & Teicoplanin & $1(1.2)$ & $7(13.7)$ & 8.576 & $0.003 *$ \\
\hline & Vancomycin & $0(0)$ & $0(0)$ & NA & NA \\
\hline
\end{tabular}




\subsection{Molecular Characterization of MRSA \\ 3.3.1. SCCmec Typing}

All (100\%) of the 132 MRSA isolates harbored the mecA gene (Figure S1). The SCCmec typing results showed the presence of SCCmec types IV $(50.6 \%)$ and V $(66.7 \%)$ among CAMRSA. HA-MRSA predominantly carried SCCmec types III (19.6\%) and I (41.2\%) (Table 3, Figures S2-S5). Further, HA-MRSA isolates harbored SCCmec types IV (31.4\%) and V (25.5\%). SCCmec types IV and V and PVL were detected together in $12.3 \%$ of CA-MRSA.

Table 3. Prevalence of the SCCmec and PVL genes among the MRSA isolates.

\begin{tabular}{|c|c|c|c|c|c|c|}
\hline \multirow{3}{*}{ Gene } & \multirow{3}{*}{$\mathbf{N} / \mathbf{P}$} & \multicolumn{3}{|c|}{ MRSA $(n=132)$} & \multirow{3}{*}{$\begin{array}{l}\text { Chi-Square } \\
\text { Value }\end{array}$} & \multirow{3}{*}{$p$-Value } \\
\hline & & \multirow{2}{*}{ CAMRSA $(n=81)$} & \multicolumn{2}{|l|}{ HA-MRSA $(n=51)$} & & \\
\hline & & & HA-MRSA with CA-MRSA Gene $(n=25)$ & HA-MRSA $(n=26)$ & & \\
\hline \multirow[b]{2}{*}{ mecA } & $\mathrm{N}$ & 0 & 0 & 0 & \multirow[b]{2}{*}{ NA } & \multirow[b]{2}{*}{ NA } \\
\hline & $\mathrm{P}$ & 81 & 25 & 26 & & \\
\hline \multirow{2}{*}{$\begin{array}{c}\text { SCCmec } \\
\text { type I }\end{array}$} & $\mathrm{N}$ & 81 & 25 & 5 & \multirow[b]{2}{*}{101.813} & \multirow[b]{2}{*}{$<0.001$ * } \\
\hline & $P$ & 0 & 0 & 21 & & \\
\hline \multirow{2}{*}{$\begin{array}{c}\text { SCCmec } \\
\text { type II }\end{array}$} & $\mathrm{N}$ & 81 & 25 & 26 & \multirow{2}{*}{ NA } & \multirow{2}{*}{ NA } \\
\hline & $\mathrm{P}$ & 0 & 0 & 0 & & \\
\hline \multirow{2}{*}{$\begin{array}{l}\text { SCCmec } \\
\text { type III }\end{array}$} & $\mathrm{N}$ & 81 & 25 & 16 & \multirow{2}{*}{44.111} & \multirow{2}{*}{$<0.001$ * } \\
\hline & $\mathrm{P}$ & 0 & 0 & 10 & & \\
\hline \multirow{2}{*}{$\begin{array}{l}\text { SCCmec } \\
\text { type IV }\end{array}$} & $\mathrm{N}$ & 40 & 9 & 26 & \multirow[b]{2}{*}{26.001} & \multirow[b]{2}{*}{$<0.001$ * } \\
\hline & $\mathrm{P}$ & 41 & 16 & 0 & & \\
\hline \multirow{2}{*}{$\begin{array}{c}\text { SCCmec } \\
\text { type V }\end{array}$} & $\mathrm{N}$ & 27 & 12 & 26 & \multirow{2}{*}{35.018} & \multirow{2}{*}{$<0.001$ * } \\
\hline & $\mathrm{P}$ & 54 & 13 & 0 & & \\
\hline \multirow{2}{*}{ PVL } & $\mathrm{N}$ & 24 & 3 & 22 & \multirow{2}{*}{33.833} & \multirow{2}{*}{$<0.001 *$} \\
\hline & $\mathrm{P}$ & 57 & 22 & 4 & & \\
\hline
\end{tabular}

N/P- Negative/Positive, NA- Not applicable, * significant.

\subsubsection{Distribution of the lukS/F-PV Gene in MRSA}

In this study, $70.4 \%$ of CA-MRSA isolates were PVL-positive based on the PCR amplification of the lukS/F-PV gene (Figure S6). PVL was found in $43.1 \%$ of MRSA isolates from patients with hospital-associated risk factors, which also showed the presence of SCCmec type IV and SCCmec type V. Among the true HA-MRSA, only $7.8 \%$ possessed the PVL gene.

\section{Discussion}

\subsection{Prevalence of CA-MRSA in Clinical Specimens}

This study shows the prevalence of CA-MRSA in patients without risk factors and in patients with risk factors for hospital-associated infection, as reported by previous studies [6,7]. We report a high prevalence (81 isolates, $61.4 \%$ ) of CA-MRSA among the MRSA isolates of this study. A study from a rural area in Andhra Pradesh, India showed a CA-MRSA prevalence of $64.7 \%$ [34]. Other reports on CA-MRSA in India were by D'Souza et al. [11] from Mumbai, Shenoy et al. [35] from Mangalore and Bouchiat et al. from Bangalore [36]. Goud et al. reported a nasal carriage rate of $72.7 \%$ for MRSA in healthy individuals in Bangalore, India [37]. A study conducted by the Indian Network for Surveillance of Antimicrobial Resistance (INSAR) group, India from January 2008 to December 2009 in 15 tertiary care centers reported an overall MRSA prevalence of 41\% [38] A meta-analysis on CA-MRSA carriage in the Asia-Pacific region from 2000-2016 showed a $0 \%$ to $23.5 \%$ occurrence in the general public and $0.7 \%$ to $10.4 \%$ occurrence in hospital settings, and reported the highest carriage rate of $16.5 \%$ to $23.5 \%$ in India [39]. CA-MRSA prevalence varies worldwide [40-42]. A study from southwest Finland reported increasing CA-MRSA cases from 13\% in 2007 to 43\% in 2016 [43]. In Denmark, ST97-IVa MRSA clone was responsible for sporadic outbreaks in a surgical ward over a period of four years [44].

In this study, MRSA was isolated from patients with mild skin infections to severe systemic disease. The clinical details showed no significant difference $(p>0.05)$ between the different age groups and gender of patients with respect to the prevalence of CA-MRSA 
and HA-MRSA. CA-MRSA was almost equally isolated from outpatients (44.4\%) and inpatients $(55.6 \%)$, suggesting the prevalence of CA-MRSA in community and hospital settings alike, while $96.1 \%$ of HA-MRSA was from inpatients. A study by the INSAR group reported the isolation of MRSA from $43 \%$ of outpatients and $42 \%$ of inpatients [38]. In our study, no significant difference $(p>0.05)$ in the mortality rate was recorded between CA-MRSA and HA-MRSA patients.

\subsection{Molecular Characterization of MRSA Isolates}

The MRSA were further categorized by SCCmec typing and the presence of the PVL gene by PCR. Based on the CDC definition of no hospital-associated risk factors and the results of SCCmec typing, 81 isolates were classified as true CA-MRSA. These included SCCmec type IV (41 isolates, 50.6\%), SCCmec type V (54 isolates, 66.7\%) and PVL-positive isolates (57 isolates, 70.4\%). A study from Mumbai, India reported the prevalence of SCCmec type IV (34.4\%), SCCmec type V (41\%) and PVL (64\%) in MRSA isolates [13]. In our study, the higher prevalence of the PVL gene (70.4\%) in CA-MRSA might suggest the frequent occurrence of virulent strains of CA-MRSA in inpatient and outpatient MRSA cases. Other studies from India corroborate our finding of a higher prevalence of the PVL gene in CA-MRSA. A study from North India reported PVL in 56.9\% of CA-MRSA [45], while a study from Belgaum, India reported an $85.1 \%$ prevalence of PVL in MRSA [46]. In this study, the three genes SCCmec type IV, SCCmec type V and PVL were detected together in $12.3 \%$ of CA-MRSA.

Of 51 HA-MRSA isolates in this study, 16(31.4\%) isolates had SCCmec type IV, 13(25.5\%) isolates had SCCmec type V, while the PVL gene was found in 22 isolates (43.1\%). This is significant and might suggest the infiltration of CA-MRSA into hospital settings. Our observations are in line with a previous study from Mumbai in which $21 \%$ of MRSA strains isolated from patients with risk factors had SCCmec type IV or SCCmec type V [13]. A similar report from Chennai, India found 44.4\% HA-MRSA with SCCmec type IV and SCCmec type V [47]. However, future studies employing whole genome sequencing will shed light on how CA-MRSA evolve to establish in hospital environments and cause infections.

This study suggests that virulent strains of CA-MRSA can be encountered in hospital settings and cause severe infections, which can delay the patient prognosis in the absence of a systematic diagnosis. The presence of SCCmec type IV and SCCmec type V in considerable percentages of $S$. aureus isolated from MRSA cases belonging to different medical departments is a cause for concern. The sources of CA-MRSA in the hospital environment could be the patients, MRSA carrier individuals attending the hospital or the medical staff. Of 51 HA-MRSA isolates, 25 were true HA-MRSA with SCCmec type I and SCCmec type III, and $7.8 \%$ of these harbored the PVL gene. None of the HA-MRSA isolates showed the presence of SCCmec type II, an observation in agreement with previous studies from India $[13,20]$. The presence of PVL in multidrug-resistant (MDR) HA-MRSA isolates can potentially complicate the treatment.

\subsection{Antibiotic Resistance}

Studies have shown that CA-MRSA are more susceptible to non- $\beta$-lactam antibiotics compared to HA-MRSA [48,49]. In this study, 23 antibiotics were used to understand the antibiotic resistance profiles of MRSA isolates. CA-MRSA and HA-MRSA showed a significant $(p<0.05)$ difference in their susceptibilities to $\beta$-lactam and non- $\beta$-lactam antibiotics. Susceptibility to non- $\beta$-lactam antibiotics has been previously reported by several investigators $[13,35,49]$. In this study, MRSA from patients with hospital-associated risk factors and harboring the SCCmec type IV and SCCmec type V genes showed a higher antibiotic resistance similar to HA-MRSA.

In our study, CA-MRSA isolates resistant to three or more classes of antibiotics were found. These isolates were resistant to cefotaxime (44.4\%), gentamicin (40.7\%), ciprofloxacin $(86.4 \%)$, clindamycin $(40.7 \%)$, erythromycin (66.7\%) and ofloxacin $(49.4 \%)$. All (100\%) MRSA isolates were resistant to penicillin, ampicillin, cefoxitin and oxacillin, while none 
showed resistance to amikacin and vancomycin. CA-MRSA was largely susceptible to netilmicin, linezolid, tigecycline, doxycycline, chloramphenicol, rifampicin and teicoplanin. A study from India reported CA-MRSA resistant to gentamicin (69\%), erythromycin (62\%), cotrimoxazole (58.6\%) and ciprofloxacin (79.3\%) [36]. MDR CA-MRSA has been reported from India and worldwide [16-18,34,50].

The emerging MDR resistance pattern of CA-MRSA has to be controlled with proper antibiotic stewardship.CA-MRSA isolated from patients with hospital-associated risk factors with MDR similar to HA-MRSA can lead to the spread of multidrug-resistant virulent strains of CA-MRSA in the hospital and the community.

The molecular characterization results show an increasing trend in the prevalence of MRSA in the general population and the presence of CA-MRSA in the hospital environment as well as in patients with hospital-associated risk factors. This emphasizes that the diagnosis of CA-MRSA should not be strictly based on the risk factors but on standard diagnostic tools such as molecular characterization by PCR and antibiotic susceptibility profiles in order to avoid treatment failures.

\section{Conclusions}

This study reports the prevalence of CA-MRSA in community and hospital settings, and the study suggests the possibility of MDR CA-MRSA replacing HA-MRSA in hospitals. This needs an action plan with proper antibiotic stewardship and treatment regime in order to control the spread of CA-MRSA in hospitals and in the community. The implementation of strict aseptic techniques in hospitals to prevent the colonization of the hospital environment by resistant strains, the identification and treatment of carriers, and the screening of hospital staff and facilities are some of the key measures that can mitigate the spread of CA-MRSA.

Supplementary Materials: The following are available online at https:/ /www.mdpi.com/2079-6 382/10/2/197/s1, Table S1: Primers used for the amplification of SCCmec and PVL gene, Table S2: Prevalence of MRSA among inpatients and outpatients, Table S3: Prevalence of MRSA among patients of different age, Table S4: Prevalence of MRSA among males and females, Table S5: Outcome of patients with MRSA cases; Figure S1: PCR assay for detection of mecA gene in MRSA isolates; Figure S2: PCR assay for detection of SCCmec type IV in MRSA isolates; Figure S3: PCR assay for detection of SCCmec type V in MRSA isolates; Figure S4: PCR assay for detection of SCCmec type III in MRSA isolates; Figure S5: PCR assay for detection of SCCmec type I in MRSA isolates; Figure S6: PCR assay for detection of PVL gene in MRSA isolates.

Author Contributions: V.S. conceptualized, planned and supervised the study; P.P.P. collected the samples, performed the laboratory analysis and compiled the data. S.H.K. analyzed and interpreted the data. P.P.P. wrote the draft manuscript; V.S. and S.H.K. critically reviewed and edited the manuscript; All authors have read and agreed to the published version of the manuscript.

Funding: This research received no external funding.

Institutional Review Board Statement: The study was conducted according to the guidelines of the Declaration of Helsinki, and approved by the Central Ethical Committee, Nitte (Deemed to be University) Ref: NU/CEC/Ph.D-65/2012 on 16-11-2012.

Informed Consent Statement: Informed consent was obtained from all subjects involved in the study.

Data Availability Statement: The data presented in this study are available on request from the corresponding author.

Acknowledgments: The authors gratefully acknowledge KS Hegde Medical Academy, Nitte (Deemed to be University), Mangalore for supporting the successful conduct of the research. The authors acknowledge Fisheries College, Mangalore for the technical support provided and Malathi Shekhar (Bioinformatics Department, Fisheries College, Mangalore) for the support in the nucleotide sequence analysis in the research work.

Conflicts of Interest: The authors declare no conflict of interest. 


\section{References}

1. Harkins, C.P.; Pichon, B.; Doumith, M.; Parkhill, J.; Westh, H.; Tomasz, A.; De Lencastre, H.; Bentley, S.D.; Kearns, A.M.; Holden, M.T.G. Methicillin-resistant Staphylococcus aureus emerged long before the introduction of methicillin into clinical practice. Genome Biol. 2017, 18,1-11. [CrossRef]

2. Chambers, H. The Changing Epidemiology of Staphylococcus aureus? Emerg. Infect. Dis. 2001, 7, 178-182. [CrossRef]

3. Mairi, A.; Touati, A.; Lavigne, J.-P. Methicillin-Resistant Staphylococcus aureus ST80 Clone: A Systematic Review. Toxins 2020, 12, 119. [CrossRef] [PubMed]

4. Naimi, T.S.; LeDell, K.H.; Como-Sabetti, K.; Borchardt, S.M.; Boxrud, D.J.; Etienne, J.; Johnson, S.K.; Vandenesch, F.; Fridkin, S.; O'Boyle, C.; et al. Comparison of Community- and Health Care-Associated Methicillin-Resistant Staphylococcus aureus Infection. JAMA 2003, 290, 2976-2984. [CrossRef] [PubMed]

5. Huang, Y.; Tseng, S.; Hu, J.; Tsai, J.; Hsueh, P.; Teng, L. Clonal spread of SCCmec type IV methicillin-resistant Staphylococcus aureus between community and hospital. Clin. Microbiol. Infect. 2007, 13, 717-724. [CrossRef]

6. Nakaminami, H.; Takadama, S.; Ito, A.; Hasegawa, M.; Jono, C.; Noguchi, M.; Shoshi, M.; Wajima, T.; Fujii, T.; Maruyama, H.; et al. Characterization of SCCmec type IV methicillin-resistant Staphylococcus aureus clones increased in Japanese hospitals. J. Med Microbiol. 2018, 67, 769-774. [CrossRef] [PubMed]

7. David, M.Z.; Cadilla, A.; Boyle-Vavra, S.; Daum, R.S. Replacement of HA-MRSA by CA-MRSA infections at an academic medical center in the midwestern United States, 2004-5 to 2008. PLoS ONE 2014, 9, e92760. [CrossRef] [PubMed]

8. Buck, J.M.; Como-Sabetti, K.; Harriman, K.H.; Danila, R.N.; Boxrud, D.J.; Glennen, A.; Lynfield, R. Community-associated Methicillin-resistant Staphylococcus aureus, Minnesota, 2000-2003. Emerg. Infect. Dis. 2005, 11, 1532-1538. [CrossRef]

9. Gillet, Y.; Issartel, B.; Vanhems, P.; Fournet, J.-C.; Lina, G.; Bes, M.; Vandenesch, F.; Piémont, Y.; Brousse, N.; Floret, D.; et al. Association between Staphylococcus aureus strains carrying gene for Panton-Valentine leukocidin and highly lethal necrotising pneumonia in young immunocompetent patients. Lancet 2002, 359, 753-759. [CrossRef]

10. Ahmad, N.I.; Yean, C.Y.; Foo, P.C.; Safiee, A.W.M.; Hassan, S.A. Prevalence and association of Panton-Valentine Leukocidin gene with the risk of sepsis in patients infected with Methicillin Resistant Staphylococcus aureus. J. Infect. Public Health 2020, 13, 1508-1512. [CrossRef]

11. De Lencastre, H.; Oliveira, D.; Tomasz, A. Antibiotic resistant Staphylococcus aureus: A paradigm of adaptive power. Curr. Opin. Microbiol. 2007, 10, 428-435. [CrossRef]

12. Andrade, M.M.; Luiz, W.B.; Souza, R.D.S.O.; Amorim, J.H. The History of Methicillin-Resistant Staphylococcus aureus in Brazil. Can. J. Infect. Dis. Med. Microbiol. 2020, 2020, 1-18. [CrossRef]

13. D'Souza, N.; Rodrigues, C.; Mehta, A. Molecular characterization of methicillin-resistant Staphylococcus aureus with emergence of epidemic clones of sequence type (ST) 22 and ST 772 in Mumbai, India. J. Clin. Microbiol. 2010, 48, 1806-1811. [CrossRef]

14. Rossato, A.M.; Primon-Barros, M.; Rocha, L.D.L.; Reiter, K.C.; Dias, C.A.G.; D'Azevedo, P.A. Resistance profile to antimicrobials agents in methicillin-resistant Staphylococcus aureus isolated from hospitals in South Brazil between 2014-2019. Rev. Soc. Bras. Med. Trop. 2020, 53, e20200431. [CrossRef]

15. A Nichol, K.; Adam, H.J.; Golding, G.R.; Lagacé-Wiens, P.R.S.; A Karlowsky, J.; Hoban, D.J.; Zhanel, G.G.; Baxter, M.R.; Walkty, A.; Blondeau, J.; et al. Characterization of MRSA in Canada from 2007 to 2016. J. Antimicrob. Chemother. 2019, 74, iv55-iv63. [CrossRef]

16. Earls, M.R.; Kinnevey, P.M.; Brennan, G.I.; Lazaris, A.; Skally, M.; O'Connell, B.; Humphreys, H.; Shore, A.C.; Coleman, D.C. The recent emergence in hospitals of multidrug-resistant community-associated sequence type 1 and spa type t127 methicillin-resistant Staphylococcus aureus investigated by whole-genome sequencing: Implications for screening. PLoS ONE 2017, 12, e0175542. [CrossRef]

17. Wang, L.; Liu, Y.; Yang, Y.; Huang, G.; Wang, C.; Deng, L.; Zheng, Y.; Fu, Z.; Li, C.; Shang, Y.; et al. Multidrug-resistant clones of community-associated meticillin-resistant Staphylococcus aureus isolated from Chinese children and the resistance genes to clindamycin and mupirocin. J. Med. Microbiol. 2012, 61, 1240-1247. [CrossRef]

18. Lee, G.C.; Dallas, S.D.; Wang, Y.; Olsen, R.J.; Lawson, K.A.; Wilson, J.; Frei, C.R. Emerging multidrug resistance in communityassociated Staphylococcus aureus involved in skin and soft tissue infections and nasal colonization. J. Antimicrob. Chemother. 2017, 72, 2461-2468. [CrossRef]

19. Kobayashi, T.; Nakaminami, H.; Ohtani, H.; Yamada, K.; Nasu, Y.; Takadama, S.; Noguchi, N.; Fujii, T.; Matsumoto, T. An outbreak of severe infectious diseases caused by methicillin-resistant Staphylococcus aureus USA300 clone among hospitalized patients and nursing staff in a tertiary care university hospital. J. Infect. Chemother. 2020, 26, 76-81. [CrossRef]

20. Abimannan, N.; Sumathi, G.; Krishnarajasekhar, O.; Sinha, B.; Krishnan, P. Clonal Clusters and Virulence Factors of MethicillinResistant Staphylococcus Aureus: Evidence for Community-Acquired Methicillin-Resistant Staphylococcus Aureus Infiltration into Hospital Settings in Chennai, South India. Indian J. Med. Microbiol. 2019, 37, 326-336. [CrossRef]

21. Choo, E.J. Community-Associated Methicillin-Resistant Staphylococcus aureus in Nosocomial Infections. Infect. Chemother. 2017, 49, 158-159. [CrossRef]

22. Kateete, D.P.; Bwanga, F.; Seni, J.; Mayanja, R.; Kigozi, E.; Mujuni, B.; Ashaba, F.K.; Baluku, H.; Najjuka, C.F.; Källander, K.; et al. CA-MRSA and HA-MRSA coexist in community and hospital settings in Uganda. Antimicrob. Resist. Infect. Control. 2019, 8, 1-9. [CrossRef] 
23. Chuang, Y.Y.; Huang, Y.C. Molecular epidemiology of community associated meticillin-resistant Staphylococcus aureus in Asia. Lancet Infect. Dis. 2013, 13, 698-708. [CrossRef]

24. Dhawan, B.; Rao, C.; Udo, E.E.; Gadepalli, R.; Vishnubhatla, S.; Kapil, A. Dissemination of methicillin-resistant Staphylococcus aureus SCCmec type IV and SCCmec type V epidemic clones in a tertiary hospital: Challenge to infection control. Epidemiol. Infect. 2015, 143, 343-353. [CrossRef]

25. Yamuna, D.; Francis, Y.; Doss, G.P.; Balaji, V. Molecular characterization of Panton-Valentine leukocidin (PVL) toxin-encoding phages from South India. New Microbes New Infect. 2017, 20, 34-38. [CrossRef]

26. Forbes, B.A.; Sahm, D.F.; Weissfeld, A.S.; Bailey, W.R. Bailey E Scott's Diagnostic Microbiology; Elsevier Mosby: St. Louis, MO, USA, 2007.

27. Broekema, N.M.; Van, T.T.; Monson, T.A.; Marshall, S.A.; Warshauer, D.M. Comparison of cefoxitin and oxacillin disk diffusion methods for detection of mecA-mediated resistance in Staphylococcus aureus in a large-scale study. J. Clin. Microbiol. 2009, 47, 217-219. [CrossRef] [PubMed]

28. Khan, A.; Wilson, B.; Gould, I.M. Current and future treatment options for community-associated MRSA infection. Expert Opin. Pharmacother. 2018, 19, 457-470. [CrossRef] [PubMed]

29. Morrison, M.A.; Hageman, J.C.; Klevens, R.M. Case definition for community-associated methicillin-resistant Staphylococcus aureus. J. Hosp. Infect. 2006, 62, 24. [CrossRef] [PubMed]

30. CLSI. Performance Standards for Antimicrobial Susceptibility Testing, 30th ed.; CLSI supplement M100; Clinical and Laboratory Standards Institute: Wayne, PA, USA, 2020.

31. Oliveira, D.C.; de Lencastre, H. Multiplex PCR strategy for rapid identification of structural types and variants of the mec element in methicillin-resistant Staphylococcus aureus. Antimicrob. Agents Chemother. 2002, 46, 2155-2161. [CrossRef]

32. Zhang, K.; McClure, J.-A.; Elsayed, S.; Louie, T.; Conly, J.M. Novel Multiplex PCR Assay for Characterization and Concomitant Subtyping of Staphylococcal Cassette Chromosome mec Types I to V in Methicillin-Resistant Staphylococcus aureus. J. Clin. Microbiol. 2005, 43, 5026-5033. [CrossRef]

33. Asghar, A.H. Molecular characterization of methicillin-resistant Staphylococcus aureus isolated from tertiary care hospitals. Pak J. Med. Sci. 2014, 30, 698-702. [CrossRef]

34. Alvarez-Uria, G.; Reddy, R. Prevalence and Antibiotic Susceptibility of Community-Associated Methicillin-Resistant Staphylococcus aureus in a Rural Area of India: Is MRSA Replacing Methicillin-Susceptible Staphylococcus aureus in the Community? ISRN Dermatol. 2012, 2012, 1-5. [CrossRef]

35. Bhat, G.K.; Kishore, A.; Hassan, M.K.; Shenoy, M.S. Significance of MRSA strains in community associated skin and soft tissue infections. Indian J. Med. Microbiol. 2010, 28, 152-154. [CrossRef]

36. Bouchiat, C.; El-Zeenni, N.; Chakrakodi, B.; Nagaraj, S.; Arakere, G.; Etienne, J. Epidemiology of Staphylococcus aureus in Bangalore, India: Emergence of the ST217 clone and high rate of resistance to erythromycin and ciprofloxacin in the community. New Microbes New Infect. 2015, 7, 15-20. [CrossRef]

37. Goud, R.; Gupta, S.; Neogi, U.; Agarwal, D.; Naidu, K.; Chalannavar, R. Commuinty prevalence of methicillin and vancomycin resistant Staphylococcus aureus in and around Bangalore, Southern India. Rev. Soc. Bras. Med. Trop. 2011, 44, 309-312. [CrossRef]

38. Indian Network for Surveillance of Antimicrobial Resistance (INSAR) Group, India. Methicillin resistant Staphylococcus aureus (MRSA) in India: Prevalence \& susceptibility pattern. Indian J. Med. Res. 2013, 137, 363-369.

39. Wong, J.W.; Ip, M.; Tang, A.; Wei, V.W.; Wong, S.Y.S.; Riley, S.; Read, J.M.; Kwok, K.O. Prevalence and risk factors of communityassociated methicillin-resistant Staphylococcus aureus carriage in Asia-Pacific region from 2000 to 2016: A systematic review and meta-analysis. Clin. Epidemiol. 2018, 10, 1489-1501. [CrossRef]

40. Saxena, S.; Singh, K.; Talwar, V. Methicillin-resistant Staphylococcus aureus prevalence in community in the east Delhi area. Jpn. J. Infect. Dis. 2003, 56, 54-56.

41. Otter, J.A.; French, G.L. Molecular epidemiology of community-associated meticillin-resistant Staphylococcus aureus in Europe. Lancet Infect. Dis. 2010, 10, 227-239. [CrossRef]

42. Dukic, V.M.; Lauderdale, D.S.; Wilder, J.; Daum, R.S.; David, M.Z. Epidemics of Community-Associated Methicillin-Resistant Staphylococcus aureus in the United States: A Meta-Analysis. PLoS ONE 2013, 8, e52722. [CrossRef]

43. Junnila, J.; Hirvioja, T.; Rintala, E.; Auranen, K.; Rantakokko-Jalava, K.; Silvola, J.; Lindholm, L.; Gröndahl-Yli-Hannuksela, K.; Marttila, H.; Vuopio, J. Changing epidemiology of methicillin-resistant Staphylococcus aureus in a low endemicity area-New challenges for MRSA control. Eur. J. Clin. Microbiol. Infect. Dis. 2020, 39, 2299-2307. [CrossRef] [PubMed]

44. Rubin, I.M.; Hansen, T.A.; Klingenberg, A.M.; Petersen, A.M.; Worning, P.; Westh, H.; Bartels, M.D. A Sporadic Four-Year Hospital Outbreak of a ST97-IVa MRSA With Half of the Patients First Identified in the Community. Front. Microbiol. 2018, 9, 1494. [CrossRef] [PubMed]

45. ul Bashir, Y.; Bali, N.; Sharma, S.; Jahan, T.; Shafi, H. SCCmec Type IV and V Methicillin Resistant Staphylococcus aureus Intrusion in Healthcare Settings. Am. J. Clin. Microbiol. Antimicrob. 2019, 2, 1032.

46. Kaur, H.; Purwar, S.; Saini, A.; Kaur, H.; Karadesai, S.G.; Kholkute, S.D.; Roy, S. Status of methicillin resistant Staphylococcus aureus infections and evaluation of PVL producing strains in Belgaum, South India. JKIMSU 2012, 2, 43-51.

47. Archana, G.J.; Sinha, A.Y.; Annamanedi, M.; Asrith, K.P.; Kale, S.B.; Kurkure, N.V.; Doijad, S.P.; Nagamani, K.; Hegde, N.R. Molecular Characterisation of Methicillin-Resistant Staphylococcus aureus Isolated from Patients at a Tertiary Care Hospital in Hyderabad, South India. Indian J. Med. Microbiol. 2020, 38, 183-192. [CrossRef] 
48. Fey, P.D.; Saïd-Salim, B.; Rupp, M.E.; Hinrichs, S.H.; Boxrud, D.J.; Davis, C.C.; Kreiswirth, B.N.; Schlievert, P.M. Comparative molecular analysis of community- or hospital-acquired methicillin-resistant Staphylococcus aureus. Antimicrob. Agents Chemother. 2003, 47, 196-203. [CrossRef]

49. Vysakh, P.R.; Jeya, M. A comparative analysis of community acquired and hospital acquired methicillin resistant Staphylococcus aureus. J. Clin. Diagn. Res. 2013, 7, 1339-1342.

50. Singh, T.; Bhutia, K.O.; Adhikari, L.; Biswas, S. Molecular characterization of community- \& hospital-acquired methicillin-resistant \& methicillin-sensitive Staphylococcus aureus isolates in Sikkim. Indian J. Med. Res. 2015, 142, 330-335. [CrossRef] 